\title{
Factors Affecting Usage of Mobile Money Services and Their Impact on Financial Inclusion: Case of Lusaka Province
}

\author{
Chanda Collins Njele ${ }^{1} \&$ Jackson Phiri ${ }^{2}$ \\ ${ }^{1}$ Graduate School of Business, University of Zambia, Lusaka, Zambia \\ ${ }^{2}$ School of Natural Sciences, Dept. of Computer Science, University of Zambia, Lusaka, Zambia \\ Correspondence: Chanda Collins Njele, Graduate School of Business, University of Zambia, Lusaka, Zambia. E- \\ mail: chanda.njele@gmail.com
}

Received: March 24, 2021

doi:10.5539/ijbm.v16n7p104
Accepted: June 5, 2021

Online Published: June 18, 2021

\begin{abstract}
This article presents a study of factors affecting the usage of mobile money services (MMS). Thirty-three User technology adoption variables relating to factors that affect MMS usage were identified, and Factor analysis was used to extract the key factors using principal component analysis. With set cut-off values, eight factors emerged with values of Communalities ( $>0.5)$, Eigenvalues $(>1)$, Percent of Cumulative Variance Explained ( $>60$ per cent), and Factor Loadings $(>0.4)$ with a total variance of $75.179 \%$. Multiple regression was conducted to see if the independent variables predicted the level of usage of MMS. The validity of the items used in this study was established by using confirmatory factor analysis. Results showed that the adoption of mobile money service is influenced by Perceived ease of use, Perceived usefulness, Perceived cost, and Perceived network quality. The perceived cost was found to have a negative influence on financial service adoption.
\end{abstract}

Keywords: Mobile Money Services, Factors Analysis, Principal component analysis, Confirmatory factor analysis

\section{Introduction}

The developments in mobile technologies have had tremendous effects on the physical products side and the nature of services provided in the world today. Diniz et al. (2011) stated that mobile technology, when used and applied as a payment channel, create an opportunity for financial inclusion amongst the unbanked population while on the supply side creates opportunities for financial institutions to deliver a wide range of services at a minimum, mostly to people living in remote areas (Diniz et al., 2011; Aker and Mbiti, 2010).

GSMA (2010) defines Mobile Money as a "service in which the mobile phone is used to access financial services". MMS plays a vital role in the economic development of a country like Zambia. According to the IFC (2011) report, mobile money services involve, among others, the transfer of cash via mobile phones and both individuals, and small businesses, use this innovation to transfer money. It refers to mobile phones' use to perform financial and banking functions (IFC Mobile Money report, 2011). This definition encompasses several services, which include payments (for instance, person-to-person transfers, utility payments), finance (for instance, insurance products), and mobile banking (for instance., account balance inquiries), among others (Donovan 2012; Gencer 2011). Globally, the growth of mobile money has been phenomenal, particularly in developing and emerging economies where sectors of the populations that are traditionally excluded from the formal financial system are now being provided with a gateway to transformative services, including financial services and bringing more people online than ever before (GSMA 2018).

MMS providers have made rapid strides in the recent past in providing various financial services. However, a considerable portion of the population that includes the underprivileged continues to remain excluded from even the most basic financial sector opportunities and services. To address financial exclusion holistically, it is essential to ensure that a range of financial services is available to every individual. MMS's evolution has been cited as a game-changing agent (IFC Mobile Money report 2011; ITU-T 2013; EPRC 2013). Hughes and Susie (2007) posit that a mobile money subscriber can initiate various financial transactions that include the transfer of money, send remittances, make payment for goods and services purchased, without using a physical depository.

Mobile money technology is a viable platform for financial services to be extended to large segments of the population at a relatively lower cost than traditional branch banking, requiring substantial investments in 
infrastructure and personnel (Jack and Suri 2011; Nandhi 2012). The advent of MMS is characterized by the continued advancements in the mobile phone technology that has resulted in easy access to financial services even by the underprivileged. Evidence from literature review postulates that individuals opt for mobile money as a means for their daily transactions, though the adoption of mobile money has been slower for developing countries compared to developed countries. The mobile sector's remarkable progression has made an exclusive chance for delivering financial and social services through a mobile network (Kabir, 2013).

\subsection{Mobile Money Subscribers Versus Mobile Phone Subscribers in Zambia}

According to the National Payments Systems in Zambia Annual report (2019), the total number of registered mobile phone subscribers in 2019 reported by the mobile money operators (MTN, Airtel and Zamtel) increased by $12 \%$ to $17,218,310$ from $15,442,108$ in 2018 . The total number of mobile money subscribers increased marginally by $1 \%(2018: 19 \%)$ to $14,119,115$ from $13,910,712$ in 2018 out of which $4,852,040(2018: 3,443,973)$ were active mobile money subscribers.

\subsection{Statement of the Problem}

Acceptance and adoption of mobile money services technology is the key driver in determining the level of financial participation among mobile money services users. In Zambia, the ZICTA (2018) report provides evidence that the country has over $73 \%$ mobile phone users and this creates an opportunity for mobile based financial inclusion. Additionally, the Government through the Zambia's National Financial Inclusion Strategy

(NFIS) 2017-2022 demonstrates authority's active commitment to the growth of mobile money services, stressing accessibility as well as diversity, innovation and customer-centricity of products. Mobile money service providers have rolled out several initiatives embracing the Government's NFIS strategy. Even with all these positive strides that have made many aware of the services, they are not viewed as a financial tool but as an alternative to sending money among both users and non-users, as such, availability of mobile money services per se does not guarantee uptake because people's decision to adopt mobile money usage depends on various factors among them, whether they have access to conventional financial services.

It is worth noting that the level of adoption of mobile money services in Zambia is still low despite various initiatives being deployed by Mobile Network Operators. The core ICT indicators in the ZICTA report (2018) showed that there is a 73\% cell phone penetration at household level out of Zambia's total population of 15.4 million. The report also indicated that while $67.2 \%$ of the population are aware of the mobile money services, only $29.5 \%$ of individuals have used mobile money services. There is evidence that the even the $29.5 \%$ of individuals that had used MMS in Zambia were not accessing the full range and quality of services in the full context of financial inclusion, hence identifying factors that affect usage of MMS in Zambia. A comprehensive understanding of MMS for financial inclusion should consider the availability and accessibility of services, frequency of use, suitability and quality of financial options for all income levels in Zambia.

Based on the above discussion, this research seeks to assess the major factors affecting the usage of Mobile Money Services based on TAM Model and how the adoption levels can be improved in order to improve the financial inclusion in Zambia

\section{Literature Review}

A conclusion based on the literature reviewed was that factors that affect adoption and usage of MMS vary from region or country to country. However, literature has also shown that the TAM model provides insights on factors that were likely to influence technology adoption. The literature reviewed has shown that MMS is a growing trend and bridges the gap in financial inclusion, especially for the marginalized communities.

\subsection{Financial Inclusion}

Every country has a financial system comprised of financial institutions, financial markets, and financial infrastructure. This system offers financial services to individuals and firms (World Bank, 2014). Demirgüç-Kunt and Klapper (2013) define financial inclusion as 'the use of formal financial services' by these individuals and firms. The Centre for Strategy and Evaluation Services (2010) alludes that financial inclusion's objective is to extend the organized financial system's scope of activities to include within its ambit people with low incomes. However, though there are several definitions of financial inclusion, defining the term in absolute terms is challenging.

Results from the 2017 Global Findex survey by the World Bank reveal an increase in overall financial inclusion. Worldwide, $69 \%$ of the adult population had access to an account at a financial institution or a mobile money provider in 2017 , compared to $62 \%$ in 2014 . The results also suggest that mobile money is a key driver of the 
increase in account ownership. Globally, 52\% of adults made or received payments digitally at least once in the past 12 months in 2017, compared to $41 \%$ in 2014. In sub-Saharan Africa, 34\% of the adult population made or received payments digitally in 2017 , compared to $27 \%$ in 2014 . Nevertheless, 1.7 billion adults remain unbanked worldwide. The report further indicates that two (2) thirds of these adults own a mobile phone, which offers new opportunities to bring the unbanked into the financial system.

\subsection{Mobile Money and Financial Inclusion}

Literature shows that mobile money has the potential to stimulate financial inclusion for the unbanked populations. Using two datasets collected in 2007 and 2008, Jack and Suri (2011) found an increased proportion of households using mobile money to save their earnings. However, their definition of savings was limited to whether an individual had a balance reserve on their phone. Among the reasons attributed to saving money on their mobile money accounts and not elsewhere were the ease of use, safety reasons, and emergencies. Similarly, while analyzing data from 2006 and 2009 financial surveys in Kenya, Mbiti and Weil (2011) showed that mobile money's adoption decreases the use of informal saving mechanisms. Overall, evidence shows that innovations in the mobile money sector that encourage households to save through minimizing transaction costs, and the risky nature of informal saving methods increase the possibility of saving by low-income earners (Nandhi, 2012).

Oluwatayo (2012) indicates that mobile phones affect the lives of billions of people around the globe, including the poor. The changing mobile technology has revealed opportunities and allowed nearly three billion people without bank accounts to access financial services. Further, Asfaw (2015), in the study on Financial Inclusion through Mobile Banking: Challenges and Prospects, indicates that using a mobile phone for inclusive finance is crucial for countries where most of the population is unbanked or underbanked. The study attempted to identify the significant challenges and opportunities for mobile banking development in Ethiopia.

\section{Theoretical and Conceptual Frameworks}

\subsection{Theoretical Framework}

The TAM model has been used prominently within the Information Systems (IS) literature to explore technology acceptance factors. Regarding this study's objectives, the TAM model is considered the most robust and persuasive model in innovation acceptance behaviour; thus, the decision to use the theoretical model as the theoretical framework for the study.

The TAM model identified attitude toward using new technology and explained using two perceived variables usefulness and ease-of-use. Literature suggests that the TAM model has been applied to predict intentions to adopt new technology by individuals, groups, or organizations (Davies, 1989). The model suggests that perceived easeof-use, perceived usefulness, attitude regarding use, and behavioural intention will predict actual usage of technology. Additionally, the TAM has contributed to developing other theories, including the unified theory of the acceptance and use of technology (UTAUT) (Viswanath et al., 2003).

The application of TAM has also been empirically supported in the adoption of E-commerce, mobile marketing, mobile wallets, e-learning; mobile banking, Big Data, business-related technologies, and much other information (Sultan, et al., 2009; Shin et al., 2009; Abdullah et al., 2016; Isaac, et al., 2018; Okcu, et al., 2019; Kalinic, et al., 2019). Considering the mobile-money business's performance and the various determinants acquired from literature, it will be prudent to examine some key factors empirically.

\subsection{Conceptual Framework}

The study develops a model for financial inclusion using the Technology adoption model (TAM) developed by Davies (1989). According to TAM, perceived usefulness (PU) and perceived ease of use (PEU) are the most important factors determining whether the users adopt and whether they use the new technology being proposed. $\mathrm{PU}$ is the degree to which an individual believes that using a certain technology improves their performance, whereas PEU is defined as a measure to which an individual believes that using technology will be free of effort (Davies (1989).

The study analyzed the factors influencing the adoption of different mobile money services offered by the MMS providers and applied the TAM to develop a financial inclusion model, as indicated in figure 1. This flow chart based conceptual model is an adaptation from the Technology Adoption Model developed by Davies (1989). It illustrates the hypothesized relationships between research constructs that constitute the key determinants of MMS providers and Clients' adoption of mobile money services. These determinants are social, cultural, economic, political factors influencing MMS clients, PU, PEU, and attitudes towards mobile money services. 
The conceptual framework postulates that adoption of MMS by clients would improve if the users' perceived usefulness, perceived ease of use, and perceived risk were well understood. The conceptual framework indicates that MMS providers using an integrationist strategy can co-exist with all other market players to efficiently allocate capital resources to achieve financial inclusion. The MMS users' trade-off will be in the Perceived usefulness (PU) and Perceived ease of use of mobile money services.

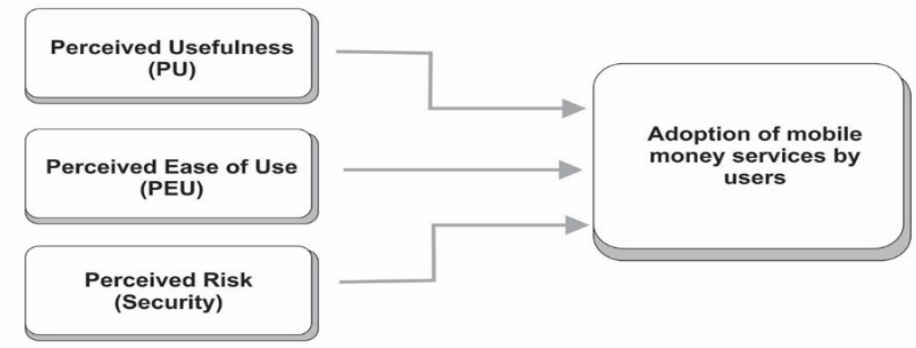

Figure 1. Conceptual framework- Adapted from Technology Adoption Model developed by Davies (1989)

\section{Methodology}

The study adopted a revised technology acceptance model (TAM) and a structured questionnaire approach to gathering data from 240 MMS Users from the Lusaka province's rural and urban areas. Using the TAM model as the basis for the theoretical and conceptual framework, thirty-three User technology adoption variables relating to factors that affect MMS usage were identified, and Factor analysis was applied to extract the key factors using principal component analysis with Varimax (orthogonal) rotation. With set cut-off values, eight factors emerged with values of Communalities ( $>0.5)$, Eigenvalues $(>1)$, Percent of Cumulative Variance Explained ( $>60$ per cent), and Factor Loadings $(>0.4)$ with a total variance of $75.179 \%$. Multiple regression was conducted to see if the independent variables predicted the level of usage of MMS. The dependent variable was the level of MMS usage, which was measured by five Likert scale items. The validity of the items used in this study was established by using confirmatory factor analysis.

\subsection{Operationalization of the Variables in Order to Develop the Questionnaire Was Adopted from the Literature}

Operationalisation of the variables in order to develop the questionnaire was adopted from the literature. The variable awareness was measured through product experience, prior usage of similar service (Liu and Tai (2016). The knowledge was operationalised as technology, performance, complexity and usage (Alkhunaizan \& Love, 2012). Based on Paylou (2003), perceived trust was measured through brand image and brand loyalty whilst perceived risk was measured through financial risk, performance risk, time risk, psychological risk and privacy risk. Further, the intention to use MMS was used to measure user intention (Hanzaee \& Adibifard, 2012).

A total of 33 constructs were identified in the study and evaluated using a Likert scale ranging from 1 to 5 interpreted as follows: 1 Not important; 2 Less important; 3 Middle important; 4 Important; 5 Very important. Therefore, the level of measurement was operationalized as a Scale or Interval. The operationalization of the constructs is presented in table 1 in Appendix A.

The results of previous studies, alongside the literature review, were employed to develop the following hypotheses: H1: The available services (perceived use) of MMS by operators influence clients' perceived usefulness.

H2: Transaction fees (Perceived Costs) structure are negative predictors of usage of MMS.

H3: The distribution network (Perceived ease of use) is a positive predictor of perceived ease of use of the MMS by users.

H4: The perceived security (Perceived Risk) of the system influences MMS adoption by users.

According to Kaasinen (2005), User's mobile money service adoption is influenced by the perception modelled by the User characteristics and environmental standings. The Technology Acceptance Model extension will be used to ground this study in adopting mobile money services by Agents and Clients/Users. The study's independent variables include the type of technology used, computer competency and knowledge of mobile money, mobile banking, gender, age, level of education, MMS operators' strategy for financial inclusion, and average monthly income. The study's dependent variable is the adoption of mobile money services technology by both the Agents 
and Clients/Users. Refer to figure 2 for a diagrammatic presentation of the hypotheses above.

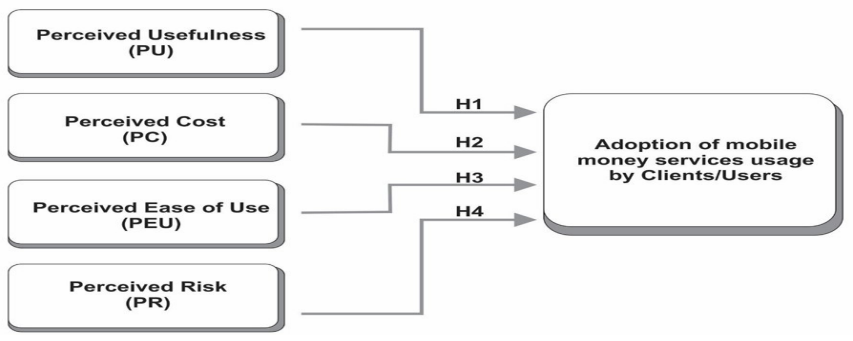

Figure 2. Hypotheses

This study applied a descriptive research design because it is best suited for gathering descriptive information. The researcher wants to know about people's feelings, attitudes, or preferences concerning one or more variables through a direct query, hence determining the relationship between the independent and dependent variables.

Based on the mix of convenience and judgmental sampling techniques, 240 respondents were selected for the study. The convenience and judgmental sampling technique were driven by respondents' availability and willingness to answer the questionnaire.

The data collection was in line with a similar study conducted by Liu and Tai (2016) based on a survey using a structured questionaire. The information in the questionnaire related to awareness/experience, knowledge, perceived trust and perceived risk in the mobile money services. The researcher gathered information using both primary and secondary data sources to collect empirical and empirically verified data according to the adopted research philosophy and gain more insights into the research problem's root cause. An electronic questionnaire using the Kobo toolbox was used to collect the primary data from the selected sample, and the secondary data was also collected from the relevant documents.

\section{Results and Discussion}

This chapter presents the findings of the study based on the data collected through field study. SPSS version 20 software was used to analyze the data. The chapter describes the respondents, characteristics, and outputs of the factor analysis. The chapter further discusses the implications of the identified factors to MMS usage. In this research, several data analysis techniques that include descriptive, factor analysis, and regression analysis were used depending on the type of data and hypothesis framed.

\subsection{Description of Respondents}

Refer to Table 2 in Appendix B for the attributes of the participants in the study.

\subsection{Presentation and Discussion of Factor Analysis Results}

The main objective of this research was to study factors affecting the usage of MMS. To fulfil the study's objective, by adapting the TAM model as the basis for the theoretical and conceptual framework, specific variables that drive user technology adoption were identified by the researcher. Thirty-three MMS user adoption variables were identified as indicated in Table 1 (Appendix A), and Factor analysis was applied to extract the key factors affecting MMS usage. According to Malhotra (2009), Factor analysis operates on the notion that measurable and observable variables can be reduced to fewer latent variables that share a common variance and are unobservable, which is known as reducing dimensionality for the current study, factor analysis was conducted to reduce the number of variables that (a) impacted individual behaviour's optimism, or pessimism (b) affects an individual's usage of MMS.

\subsubsection{Communalities}

Communality (Common variance) is the variance in a collectively shared variable among all other variables under study. The difference or variance is dependant on the variable's association with the rest of the variables in the study. The communality values of variables in Table 3, Appendix C, are showing shared variance among the variables as embodied by the extracted factors (Hair et al. 2009).

The value exhibited by the communality is a useful metric of indicating the variance showcased by an individual variable. A superior communality number showcases a higher degree of variance derived by the factor solution. A small communality number exhibits that the said variable is analytically independent and cannot be clubbed with the rest of the variables. The statistical thumb rule indicates that communalities with a value of less than 0.5 should 
be removed for further analysis. Therefore, Variable 32 was dropped in further analysis.

\subsubsection{Eigenvalue and Total Variance Explained}

Factor analysis aims to reduce several individual variables into fewer numbers that are still able to explain the whole group of variables satisfactorily. To arrive at the number of factors to be extracted or included in the analysis, some techniques for filtering and/or checkpoint for the number of factors to be pulled out are used (Hair et al. 2009). The following are examples.

\subsubsection{Eigenvalue}

Eigenvalues, also called characteristic roots, is the most general method used to measure a latent parameter. Eigenvalues show variance explained by that particular factor out of the total variance. The elementary objective behind the same is that a single factor should account for at least an individual variable variance if it needs to be included for further examination. Eigenvalue or latent root represents the total amount of variance in the dataset explained by the common factor. The general thumb rule dictates that a factor with a latent or Eigenvalue larger than one must be considered for further analysis whereas a factor with the Eigenvalue equal or less than 1 should be left out.

\subsubsection{Total Variance Explained}

The Per-cent of the variance method aims to secure a particular cumulative per cent of the whole variance pulled out by the following factors. While 100 per cent may not be attainable in social sciences, the thumb rule should not be less than 60 per cent. (Hair et al., 2009).

Table 1 contains information regarding 33 possible factors and their relative explanatory power as expressed by their eigenvalues. There is a total of eight (8) factors having eigenvalues more than 1 . Hence, the researcher retained these eight factors for further study. The total variance explained by the eight factors is $75.179 \%$. This is a fair percentage of variance to be explained and assumes the appropriateness of the factor analysis.

Table 1. Total variance explained

\begin{tabular}{|c|c|c|c|c|c|c|c|c|c|}
\hline \multirow[b]{2}{*}{ Component } & \multicolumn{3}{|c|}{ Initial Eigenvalues } & \multicolumn{3}{|c|}{ Extraction Sums of Squared Loadings } & \multicolumn{3}{|c|}{ Rotation Sums of Squared Loadings } \\
\hline & Total & $\begin{array}{l}\% \text { of } \\
\text { Variance }\end{array}$ & Cumulat & $\%$ Total & $\begin{array}{l}\% \text { of } \\
\text { Variance }\end{array}$ & Cumulative \% & Total & $\begin{array}{l}\% \text { of } \\
\text { Variance }\end{array}$ & Cumulative \% \\
\hline 1. & 8.378 & 25.389 & 25.389 & 8.378 & 25.389 & 25.389 & 8.050 & 24.395 & 24.395 \\
\hline 2. & 3.864 & 11.708 & 37.097 & 3.864 & 11.708 & 37.097 & 3.014 & 9.134 & 33.529 \\
\hline 3. & 2.791 & 13.441 & 50.537 & 2.791 & 13.441 & 50.537 & 2.442 & 7.400 & 46.961 \\
\hline 4. & 2.453 & 7.435 & 57.972 & 2.453 & 7.435 & 57.972 & 2.226 & 6.745 & 53.706 \\
\hline 5. & 2.112 & 6.399 & 64.371 & 2.112 & 6.399 & 64.371 & 2.089 & 6.330 & 60.036 \\
\hline 6. & 1.332 & 4.037 & 68.408 & 1.332 & 4.037 & 68.408 & 1.813 & 5.495 & 65.531 \\
\hline 7. & 1.181 & 3.579 & 71.986 & 1.181 & 3.579 & 71.986 & 1.768 & 5.359 & 70.890 \\
\hline 8. & 1.054 & 3.193 & 75.179 & 1.054 & 3.193 & 75.179 & 1.416 & 4.290 & 75.179 \\
\hline
\end{tabular}

Note. Extraction Method: Principal Component Analysis (SPSS V20).

\subsection{Factor Loading}

Factor loading denotes the correlation coefficient for the variable and factor. It indicates the strength of the variables that constitute the factor. Factor loading shows the variance explained by the variable on that particular factor. The larger the factor loading's absolute value, the factor and the variable are more closely interrelated. This means the more significant role the variable plays in interpreting the factor analysis. (Malhotra,

2008). The researcher's detecting principal factor loadings based on sample size was guided by Table 2 below. 
Table 2. Factor Loading Sample size needed for Significance

\begin{tabular}{ll}
\hline Factor Loading & The sample size needed for significance \\
\hline 0.30 & 350 \\
0.35 & 250 \\
0.40 & 200 \\
0.45 & 150 \\
0.50 & 120 \\
0.55 & 100 \\
0.60 & 85 \\
0.65 & 70 \\
0.70 & 60 \\
0.75 & 50 \\
\hline
\end{tabular}

As shown in Table 3 (Appendix C) and Table 5 that values of Communalities ( $>0.5$ ), Eigenvalues ( $>1)$, Percent of Cumulative Variance Explained ( $>60$ per cent), and Factor Loadings ( $>0.4)$ are greater than cut off values.

Hence, after detailed analysis, eight factors have been identified.

\subsubsection{Extraction of Factors}

Table 6 (Appendix D) shows the final factor analysis extraction with the eight identified factors that affect MMS usage. The table shows that the study investigated 33 questions relating to factors that affect Mobile Money Services usage in Zambia, which were factor analyzed using principal component analysis with Varimax (orthogonal) rotation. The analysis reveals that eight factors were extracted based on the 33 variables investigated, explaining a total of $75.179 \%$ of the variance for the entire set of variables. Refer to Appendix D,

Table 6 Rotated Component Matrix ${ }^{\mathrm{a}}$.

The first factor derived was labelled "Perceived Services" (PS) due to the high loadings by the following items: MNO Serving Services, MNO Cash Deposit Service, MNO Cash Withdraw Service, MNO Bill payment Service, MNO Airtime Purchase Service, MNO Funds Transfer Service, MNO Nkongole Service, MNO International Remittances Service as indicated in table 4 . This first factor explained $25.389 \%$ of the variance.

The second factor derived was labelled "Perceived Usage" (PU). This factor was labelled as such due to the high loadings by the following factors: level of usage - savings, airtime purchases, cash deposits, funds transfer, bill payment, and cash withdraws. The variance explained by this factor was $11.708 \%$.

The third factor derived was labelled "Perceived Challenges" (PCH). This factor was labelled as such due to the high loadings by the following factors: lack of interoperability, insufficient funds/cash at MMS points, insufficient e-float at MMS points, fraud, and frequent network breakdown indicated in table 4 . The variance explained by this factor was $13.441 \%$.

The fourth factor derived was labelled "Perceived Ease of Use" (PEU). This factor was labelled due to the high loadings by the following factors: Collaboration by mobile telephone network operators through interoperability and collaboration with other financial services providers. The variance explained by this factor was $7.435 \%$. The fifth factor derived was labelled "Perceived Costs" (PC). This factor was labelled as such due to the high loadings by the following factors: Low/same transaction costs across all channels, High transaction cost, and Cost of community education on MMS for financial inclusion. The variance explained by this factor was $6.399 \%$.

The sixth factor derived was labelled "Perceived Risk" (PR). This factor was labelled as such due to the high loadings by the following factors: Insecurity to operate MMS and access to credit. The variance explained by this factor was $4.037 \%$.

The Seventh factor derived was labelled "Regulation" (R). This factor was labelled as such due to the high loadings by the following factors: Stronger regulation by financial regulators and Enhance availability of e-banking platforms, mainly POS devices. The variance explained by this factor was $3.579 \%$.

The Eighth factor derived was labelled "Perceived Network Quality" (PNQ). This factor was labelled as such due to the high loadings by the following factors: Improve MNO Network quality. The variance explained by this factor was 3.193\%. 


\subsection{Model Specification}

\subsubsection{Model Summary}

Multiple regression was conducted to see if the independent variables predicted the level of usage of MMS. The dependent variable was the level of MMS usage, which was measured by five Likert scale items. Independent variables were Perceived services (PS), Perceived challenges (PCH), Perceived ease of use (PEU), Perceived usefulness (PU), Perceived cost (PC), Regulation (R), Perceived risk (PR), and Perceived network quality (PNQ). The validity of the items used in this study was established using confirmatory factor analysis (results in table 6). All the items have a factor loading of +5 and above, which are acceptable (Brown, 2006; Bernard, 2006; Mitchell and Jolley, 2010). Table 3 shows the Model summary.

Table 3. Model Summary ${ }^{\mathrm{b}}$

\begin{tabular}{|c|c|c|c|c|c|}
\hline Model & $\mathrm{R}$ & & Adjusted R Square & Std. Error of the Estimate & Durbin-Watson \\
\hline$\underline{1}$ & $.437^{\mathrm{a}}-$ & $\underline{\text { R Square .191 }}$ & .163 & .627 & 1.948 \\
\hline
\end{tabular}

a. Predictors: (Constant), PNQ, R, PR, PC, PEU, PU, PCH, PS.

b. Dependent Variable: Use of MMS

According to Bordens \& Abbott (2011), in the linear regression analysis, R Square provides an index of variability in the dependent variable accounted for by the predictor variables. To know if the R squared is significant, Mitchell and Jolley (2010) recommend to look at the significance of an F test of ANOVA. If it is significant, the probability of F should be less than 0.05 . The analysis revealed that Perceived services (PS), Perceived challenges (PCH), Perceived ease of use (PEU), Perceived usefulness (PU), Perceived cost (PC), Regulation (R), Perceived risk (PR), and Perceived network quality (PNQ) explain a significant amount of the variance in the usage of MMS $(\mathrm{F}(8,229)$ $=6.757, \mathrm{p}<.05, \mathrm{R}^{\wedge} 2=.19, \quad \llbracket \mathrm{R}^{\wedge} 2 \rrbracket$ (Adjusted $)=.16$ ). Refer to Table 4 for the results of the regression analysis.

Table 4. ANOVA ${ }^{\mathrm{a}}$

\begin{tabular}{llrrrrr}
\hline Model & & Sum of Squares & Df & Mean Square & F & Sig. \\
\hline \multirow{3}{*}{1} & Regression & 21.229 & 8 & 2.654 & 6.757 & $.000^{b}$ \\
& Residual & 89.930 & 229 & .393 & & \\
\cline { 2 - 6 } & Total & 111.160 & 237 & & & \\
\hline
\end{tabular}

a. Dependent Variable: Use of MMS

b. Predictors: (Constant), PNQ, R, PR, PC, PEU, PU, PCH, PS.

Table 5. Coefficients ${ }^{\mathrm{a}}$

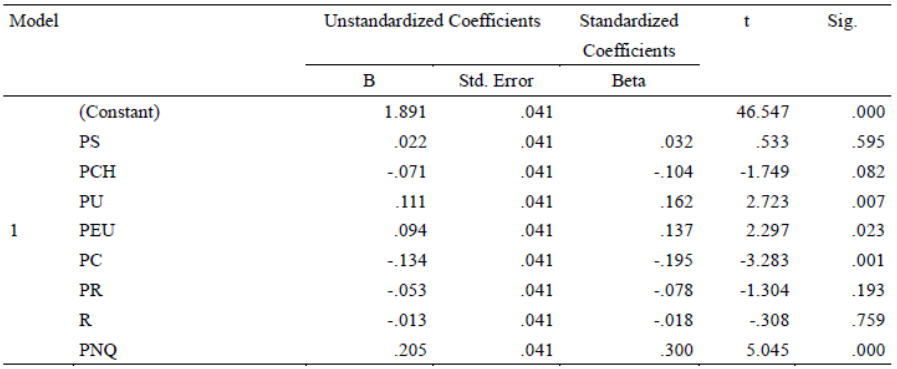

a. Dependent Variable: Use of MMS

The analysis shows that Perceived services (PS) $(\beta=.032, \mathrm{p}>.05)$, Perceived challenges (PCH) $(\beta=-0.104$, $\mathrm{p}>0.05)$, Perceived ease of use (PEU) $(\beta=0.137, \mathrm{p}<.05)$, Perceived usefulness (PU) $(\beta=0.162, \mathrm{p}<0.05)$, Perceived cost (PC) $(\beta=-0.195, p<0.05)$, Regulation (R) $(\beta=-0.018, p>.05)$, Perceived risk (PR) $(\beta=-0.078, p$ $<0.05)$ and Perceived network quality (PNQ) $(\beta=0.300, \mathrm{p}<.05)$. Therefore, the analysis shows that Perceived ease of use (PEU) $(\beta=0.137, p<.05)$, Perceived usefulness (PU) $(\beta=0.162, p<0.05)$, Perceived cost (PC) $(\beta=$ $-0.195, p<0.05)$, and Perceived network quality (PNQ) $(\beta=0.300, p<.05)$ had significant influence on the level of usage of MMS. Further, the analysis shows that Perceived services (PS) $(\beta=.032, p>.05)$, 
Perceived challenges (PCH) $(\beta=-0.104, p>0.05)$, Regulation $(\mathrm{R})(\beta=-0.018, \mathrm{p}>.05)$, and Perceived risk (PR) $(\beta$ $=-0.078, \mathrm{p}>0.05)$ had no significant influence on the level of usage of MMS.

\subsection{Hypothesis Testing}

\subsubsection{Result for Hypothesis 1 (Perceived Usefulness)}

Hypothesis one tested the influence of perceived usefulness on the usage of mobile money services. The regression analysis result revealed that perceived usefulness has a significant positive influence on mobile

money services' adoption. From the analysis, perceived usefulness has $\beta=0.162, p<0.05$, which indicates a significant positive influence on mobile money services usage.

\subsubsection{Result for Hypothesis 2 (Perceived Costs)}

The result in table 9 revealed that perceived cost (PC) has a significant negative influence on the adoption of mobile money services by users at the $\mathrm{p}<0.01$ significance level with $\beta=-0.195$. This hypothesis proposed a significant negative influence of perceived cost on adoption and was supported by the study's findings at the 0.05 significance level.

\subsubsection{Result for Hypothesis 3 (Perceived Ease of Use)}

Hypothesis 3 proposed that perceived ease of use has a significant positive influence on mobile financial services' adoption. This hypothesis was supported by the result of the analysis, which revealed that perceived ease of use significantly influenced the adoption of mobile money services. Perceived ease of use has a $\beta=0.137, p<0.05$. This hypothesis proposed a significant negative influence of perceived cost on adoption and was supported by the study's findings at the 0.05 significance level.

\subsubsection{Result for Hypothesis 4 (Perceived Risk)}

Table 9 revealed that perceived risk has no significant influence on the adoption of mobile money services. The result shows that perceived risk has a beta coefficient of $\beta=0.078, p=0.198$, which is not significant at the 0.05 significance level because the $\mathrm{p}$-value is greater than 0.05 . Therefore, based on the result of the regression analysis, this hypothesis was not supported.

\subsection{Proposed Model Based on Study Findings}

The study revealed that perceived usage and perceived ease of use are positively related to MMS usage, and this confirms traditional TAM, which was employed in this study. Based on this model, it has been found that perceived usage and perceived ease of use influence the use of MMS and perceived network quality, perceived challenges, perceived costs, and perceived risks. The study findings show that while perceived network quality positively impacts an individual's choice to use MMS, the perceived challenges, perceived costs, and perceived risk negatively impact MMS usage by individuals. Refer to figure 3 below. These findings are consistent with previous literature on the acceptance and adoption of new technologies. The model proposed by this is based on predictors that were found to be significant in the analysis. These include; Perceived ease of use (PEU) $(\beta=0.137, p<.05)$, Perceived usefulness (PU) $(\beta=0.162, p<0.05)$, Perceived cost $(\mathrm{PC})(\beta=-0.195, \mathrm{p}<0.05)$, and

Perceived network quality (PNQ) $(\beta=0.300, \mathrm{p}<.05$

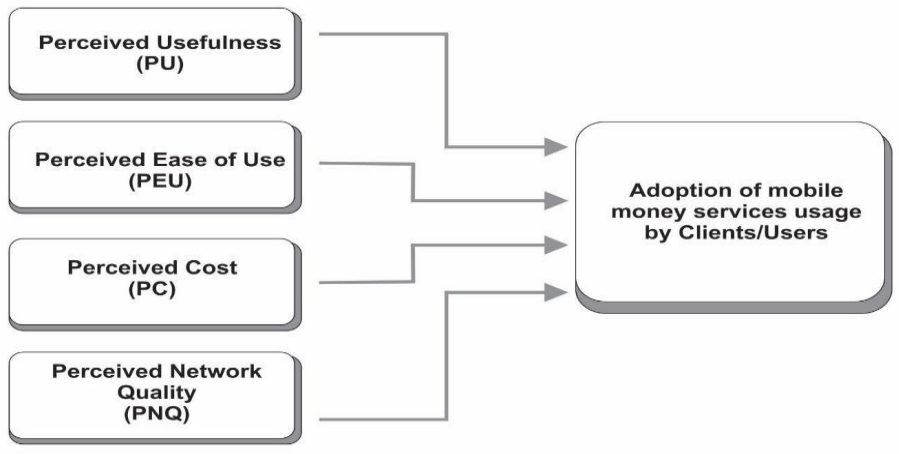

Figure 3. Proposed model based on study findings

Equation 1: MMS adoption $=\beta+P U X_{1 j}+P E U X_{2 j}+P N Q X_{3 j}-P C X_{4 j}+\varepsilon_{i}$ 
Equation 2: MMS adoption $=1.891+0.137 X_{1 j}+0.162 X_{2 j}+0.3 X_{3 j}+(-0.195) X_{4 j}+\varepsilon_{i}$

The model predicts that any increase in transaction costs negatively affects MMS usage by -0.195 units, while PNQ, PEU, and PU positively affect MMS usage by the units indicated in Equation 2.

The study showed that the adoption of mobile money service is influenced by Perceived ease of use (PEU) $(\beta=$

0.137, $\mathrm{p}<.05)$, Perceived usefulness (PU) $(\beta=0.162, \mathrm{p}<0.05)$, Perceived cost (PC) $(\beta=-0.195, \mathrm{p}<0.05)$, and Perceived network quality (PNQ) $(\beta=0.300, \mathrm{p}<.05$. The perceived cost was found to negatively influence financial service adoption with $\beta=-0.195, p<0.05$. This suggests that the high cost of mobile money services can discourage the adoption and use of these services. The study reveals that customers will accept useful mobile money services, ease to use with network compatibility, and operated on perceived network quality. The study also revealed that perceived challenges and perceived risk have no significant influence on adopting mobile money services. This study contributes to the literature on the adoption of mobile money services based on technology acceptance. The negative relationship between perceived risk and Challenges suggests that mobile money service providers have to address issues associated with risk and challenges to increase mobile money service adoption rate.

\section{Practical Implications and Recommendations}

The business implication of these findings is related to product development, pricing, and marketing. The result indicates that perceived usefulness, perceived ease of use, perceived network quality, and perceived cost significantly influence the adoption, which means that customers will adopt easily services that they perceive to be useful to their use. Providers of mobile money services have to design products with perceived usefulness and ease of use of mobile money services as they compete for market share. The perceived cost was found to have a significant negative influence on the adoption of mobile money services; this implies that increasing the access cost will reduce the rate and the speed of adoption. According to Micheni, Lule, and Muke, (2013), the cost-benefit pattern is significant to perceived usefulness and ease of use. This implies that the high cost of access to these services affects the user's perception of the usefulness and ease of use. Therefore, businesses designing affordable products can increase the adoption rate and the use of services. Moreover, mobile money service providers should consider cutting down the price of financial services to motivate more users to adopt the service and contribute toward achieving financial inclusion.

The strong influence of perceived network quality on mobile money service adoption shows the impact of changing business technology. Moreover, mobile money service providers should address all issues associated with mobile payment systems' performance regarding technology. Many respondents indicated concern about performance risk in the provision of mobile money services. This implies that there are many aspects of mobile money services which cause problems in using MMS. The perceived risk may harm users trust in the integrity of mobile money services systems. The technical aspect of mobile money services must be considered carefully before the implementation and after the implementation to minimise the possibility of risk, which may cause losses to users.

Financial inclusion policies emphasise access to financial service at an affordable price, convenience, and all users. The result provides insights into how mobile financial services can be priced, designed, and delivered to the unbanked population. The result on the perceived cost implies that these infrastructures should support providing financial services at an affordable price and services that are useful.

\section{Recommendations}

The results showed that Customers' perception of MMS product's usefulness and ease of use is key, therefore, Providers of mobile money services have to embed these two constructs in the design of their products as they compete for market share.

Given that the perceived cost was found to have a significant negative influence on the adoption of MMS, businesses must design products that are affordable to the majority of low income and unbanked population. This motivate more users to adopt the service and contribute toward achieving financial inclusion.

The results showed that perceived risk and perceived challenges may be a barrier to customer trust development, therefore, MMS providers must promptly and adequately address issues such as Cyber, loss and delays associated with risk and challenges including connectivity, float and location to increase the rate of MMS adoption

\section{Limitations and Opportunities for Future Research}

This study used a convenience sampling approach to get many respondents within the time frame of the study. According to Zikmund and Babin, (2010), respondents selected on a convenience basis may not be representative 
because of the haphazard manner by which many are selected or because of self-selection bias. Because of biasness and a haphazard selection of result projecting result beyond the specific sample may be inappropriate. Therefore, longitudinal research is recommended to be conducted to understand the influences of the adoption behaviour at a different level of market maturity and points of time.

\section{Acknowledgments}

The authors wish to acknowledge the valuable support of every one who helped in the actual distribution of the questionnaire and the respondents of the questionnaire.

\section{References}

Abdullah et al. (2016). Developing a General Extended Technology Acceptance Model for E-Learning (GETAMEL) by analyzing commonly used external factors. Comput. Hum. Behav., 56, 238-256. https://doi.org/10.1016/j.chb.2015.11.036

Aker, J. C., \& Mbiti, I. M. (2010) Mobile phones and economic development in Africa. Journal of Economic Perspectives, 24(3): 207-232. https://doi.org/10.1257/jep.24.3.207

Alkhunaizan, A., \& Love, S. (2012). What drives mobile commerce? An empirical evaluation of the revised UTAUT model. International Journal of Management and Marketing Academy, 2(1), 82-99

Asfaw, H. A. (2015). Financial Inclusion through Mobile Banking: Challenges and Prospects. Research Journal of Finance and Accounting, 6(5).

Bordens, K. S., \& Abbott, B. B. (2011). Research Design and Methods: A Process Approach (8th ed.). McGrawHill.

Collins, D., Morduch, J., Rutherford, S., \& Ruthven, O. (2009). Portfolios of the poor - how the world's poor live on $\$ 2$ a day., New Jersey, USA: Princeton University Press. https://doi.org/10.1515/9781400829965

Davies, F. (1989). Perceived Usefulness, Perceived Ease to User, and User Acceptance of Information Technology. Management Information Systems Research Center, University of Minnesota, 13(3), 319-340. https://doi.org/10.2307/249008

De Koker, L., \& Nicola, J. (2013). Financial Inclusion and Financial Integrity: Aligned Incentives? World Development, 44, 267-280. https://doi.org/10.1016/j.worlddev.2012.11.002

Demirgüç-Kunt, A., \& Klapper, L. (2013). Measuring Financial Inclusion: Explaining Variation in Use of Financial Services across and within Countries. Brookings Papers on Economic Activity, (1), 279-340. https://doi.org/10.1353/eca.2013.0002

Demirgüç-Kunt, A., \& Klapper, L. (2012) Financial inclusion in Africa: an overview. Policy Research Working Paper No. 6088. The World Bank, Washington, DC. https://doi.org/10.1596/1813-9450-6088

Diniz, E. H., Albuquerque, J. P., \& Cernev, D. K. (2011). Mobile Money and Payment: a literature review based on academic and practitioner-oriented publications (2001-2011). https://doi.org/10.2139/ssrn.2924669

Donovan, K. (2012). Mobile money for financial inclusion. In T. Kelly, N. Friederici, M. Minges and M. Yamamichi (Eds.), Information and Communications for Development: Maximising Mobile (pp. 61-74). Washington, DC: World Bank. https://doi.org/10.1596/9780821389911_ch04

Economic Policy Research Centre (EPRC). (2013). FinScope III Report. Unlocking Barriers to Financial Inclusion in Uganda. Economic Policy Research Centre.

GSMA. (2010). Mobile Money Definitions.

GSMA. (2018). State of the Industry Report on Mobile Money.

Hair et al. (2009). Multivariate Data Analysis. Prentice-Hall, New Jersey.

Hanzaee, K. H., \& Adibifard, S. (2012). Development and validation of native material values scale for Iran (NMVS-I). Research Journal of Applied Sciences, Engineering, and Technology, 4(14), 2140-2146. Retrieved from http://maxwellsci.com/print/rjaset/v4-2140-2146.pdf

Honohan, P. (2008) Cross country variation in household access to financial services. Journal of Banking and Finance, 32, 2493-2500. https://doi.org/10.1016/j.jbankfin.2008.05.004

Hughes, N., \& Lonie, S. (2007). M-PESA: Mobile Money for the "unbanked": turning cellphones into 24hour tellers in Kenya. Innovations, 2, 63-81. https://doi.org/10.1162/itgg.2007.2.1-2.63

IFC (International Finance Corporation). (2011). Mobile Money Study 2011. Washington, DC. 
http://www.ifc.org/ifcext/globalfm.nsf/Content/Mobile+Money+Study+2011.

ITU-T Technology Watch Report. (2013). The Mobile Money Revolution. Financial Inclusion Enabler. ITU-T Technology Watch Report.

Isaac et al. (2018). The effect of awareness and perceived risk on the technology acceptance model (TAM): Mobile banking in Yemen. Int. J. Serv. Stand, 12, 180-204. https://doi.org/10.1504/IJSS.2018.10012980

Jack, W., \& Suri, T. (2011). Mobile Money: the economics of M-PESA. NBER Working Paper No. 16721. National Bureau of Economic Research, Cambridge, MA. https://doi.org/10.3386/w16721

Kaasinen, E. (2005). User acceptance of mobile services values, ease of use, trust, and ease of adoption. VTT Publications, 566, 1-222.

Kabir, M. R. (2013). Factors Influencing the Usage of Mobile Banking: Incident from a Developing Country. World Review of Business Research, 3(3), 96-114.

Kalinic et al. (2019). A multi-analytical approach to peer-to-peer mobile payment acceptance prediction. J. Retail. Consum. Serv., 49, 143-153. https://doi.org/10.1016/j.jretconser.2019.03.016

Liébana-Cabanillas et al. (2018). Predicting the determinants of mobile payment acceptance: A hybrid SEM-neural network approach. Technol. Forecast. Soc. Chang., 129, 117-130. https://doi.org/10.1016/j.techfore.2017.12.015

Malhotra. (2009). Marketing Research: An Applied Orientation (6th ed.). Pearson Education.

Mbiti, I., \& Weil, D. (2011). Mobile banking: the impact of M-Pesa in Kenya. NBER Working Paper, No. 17129. https://doi.org/10.3386/w17129

Nandhi, A. M. (2012). Effects of Mobile Banking on the Savings Practices of Low-Income Users - The Indian Experience. Institute for Money, Technology \& Financial Inclusion. Working Paper 2012-7. https://doi.org/10.2307/j.ctvw04bp0.21

Oluwatayo, I. B. (2012). Mobile Phones as Mobile Banks and Credit Outlets: The Experiences of Farming Households in Rural Southwest Nigeria. International Journal of Computing and ICT Research, 6(1), 52-59.

Okcu et al. (2019). Factors Affecting Intention to Use Big Data Tools: An Extended Technology Acceptance Model. In Industrial Engineering in the Big Data Era. Lecture Notes in Management and Industrial Engineering, 401416. https://doi.org/10.1007/978-3-030-03317-0_33

Patil et al. (2017). Digital payments adoption: An analysis of literature. In Lecture Notes in Computer Science (Including Subseries Lecture Notes in Artificial Intelligence and Lecture Notes in Bioinformatics). https://doi.org/10.1007/978-3-319-68557-1_7

Paylou, P. (2003). Consumer Acceptance of Electronic Commerce: Integrating Trust and Risk with the Technology Acceptance Model. International Journal of Electronic Commerce, 7(3), 69-103.

Rhyne, E. (2012). Money Management, Financial Inclusion, and Banking the Unbanked, Center for Financial Inclusion.

Schneider, F., \& Dominik, E. (2000). Shadow economies: Size, causes, and consequences. The Journal of Economic Literature, 38(1), 77-114. https://doi.org/10.1257/jel.38.1.77

Shen et al. (2017). Trust transfer mechanism and intention on accepting NFC mobile payment: An empirical research. In Advances in Intelligent Systems and Computing. https://doi.org/10.1007/978-3-319-41956-5_32

Shin et al. (2009). Towards an understanding of the consumer acceptance of mobile wallet. Comput. Hum. Behav., 25, 1343-1354. https://doi.org/10.1016/j.chb.2009.06.001

Sultan et al. (2009). Factors Influencing Consumer Acceptance of Mobile Marketing: A Two-Country Study of Youth Markets. J. Interact. Mark., 23, 308-320. https://doi.org/10.1016/j.intmar.2009.07.003

The Centre for Strategy and Evaluation Services. (2010). Study on the Costs and Benefits of Policy Actions in the Field of Ensuring Access to a Basic Bank Account.

Viswanath et al. (2003). User Acceptance of Information Technology: Toward a Unified View. MIS Quarterly, 27(3), 425-478. https://doi.org/10.2307/30036540

Steel, W. F., Aryeetey, E., Hettige, H., \& Nissanke, M. (1997). Informal financial markets under liberalization in four African countries. World Dev., 25, 817-830. https://doi.org/10.1016/S0305-750X(96)00133-7

World Bank. (2014). Global Financial Development Report, Financial Inclusion. Retrieved from 
http://www.centerforfinancialinclusion.org

Zikmund et al. (2010). Business Research Methods, South-Western Cengage Learning.

\section{Appendix A.}

Table 1. Operationalization of variables

\begin{tabular}{|c|c|c|c|c|c|}
\hline Count & Constructs & Count & Constructs & Count & Constructs Investigated \\
\hline 1 & Depositing Cash & 12 & Savings & 23 & High transaction cost \\
\hline 2 & Withdrawing Cash & 13 & Access to credit & 23 & Insecurity to operate MMS \\
\hline 3 & Funds Transfer & 14 & $\begin{array}{l}\text { Handling } \\
\text { remittances }\end{array}$ & 124 & Fraud \\
\hline 4 & Savings & 15 & Bill payments & 25 & $\begin{array}{l}\text { Collaboration by mobile telephone network operators } \\
\text { through interoperability }\end{array}$ \\
\hline 5 & Access to credit & 16 & Airtime purchases & 26 & Collaboration with other financial services providers \\
\hline 6 & $\begin{array}{l}\text { Handling international } \\
\text { remittances }\end{array}$ & 17 & Only a few MMS access point & 27 & Improve MNO Network quality \\
\hline 7 & Bill payments & 18 & $\begin{array}{l}\text { Insufficient funds/cash at } \\
\text { MMS points }\end{array}$ & 28 & Stronger regulation by financial regulators \\
\hline 8 & Airtime purchases & 19 & $\begin{array}{l}\text { Insufficient e-float at MMS } \\
\text { points }\end{array}$ & 29 & $\begin{array}{l}\text { Enhance the availability of e-banking platforms, mainly } \\
\text { POS devices }\end{array}$ \\
\hline 9 & Depositing Cash & 20 & $\begin{array}{l}\text { MMS is too complex to } \\
\text { operate }\end{array}$ & 30 & Community education on MMS for financial inclusion \\
\hline 10 & Withdrawing Cash & 21 & Frequent Network breakdown & 31 & Integration of MMS for financial settlements \\
\hline 11 & Funds Transfer & 22 & Lack of interoperability & 33 & Low/same transaction costs across all channels. \\
\hline
\end{tabular}

\section{Apendix B}

Table 2. Sample profile

\begin{tabular}{|c|c|c|c|c|c|c|c|c|c|}
\hline \multirow{3}{*}{ Variable } & & \multirow{3}{*}{ Frequency } & \multirow{3}{*}{$\%$} & \multirow{3}{*}{ Valid \% } & \multirow{3}{*}{ Cum. \% } & \multicolumn{4}{|c|}{ Bootstrap for Percentage } \\
\hline & & & & & & Bias & Std & $95 \% \mathrm{Cc}$ & ce Interval \\
\hline & & & & & & DTas & Error & Lower & Upper \\
\hline \multirow{4}{*}{ Gender } & Male & 134 & 55.8 & 55.8 & 55.8 & -.1 & 3.2 & 49.2 & 62.1 \\
\hline & Female & 106 & 44.2 & 44.2 & 100 & .1 & 3.2 & 37.9 & 50.8 \\
\hline & Total & 240 & 100 & 100.0 & & .0 & .0 & 100.0 & 100.0 \\
\hline & $15-20$ & 20 & 8.3 & 8.3 & 8.3 & .1 & 1.8 & 5.4 & 12.1 \\
\hline \multirow{6}{*}{$\begin{array}{l}\text { Age Group } \\
\text { (Yrs) }\end{array}$} & $21-30$ & 126 & 52.5 & 52.5 & 60.8 & .0 & 3.1 & 46.7 & 58.8 \\
\hline & $31-40$ & 44 & 18.3 & 18.3 & 79.2 & -.1 & 2.5 & 13.3 & 22.9 \\
\hline & $41-50$ & 42 & 17.5 & 17.5 & 96.7 & .0 & 2.5 & 12.9 & 22.5 \\
\hline & $51-60$ & 8 & 3.3 & 3.3 & 100.0 & .0 & 1.1 & 1.3 & 5.8 \\
\hline & Total & 240 & 100.0 & 100.0 & & .0 & .0 & 100.0 & 100.0 \\
\hline & No education & 10 & 4.2 & 4.2 & 4.2 & .0 & 1.3 & 1.7 & 7.1 \\
\hline \multirow{7}{*}{$\begin{array}{l}\text { Level of } \\
\text { Education }\end{array}$} & Primary & 32 & 13.3 & 13.3 & 17.5 & .0 & 2.2 & 9.2 & 17.9 \\
\hline & Secondary & 102 & 42.5 & 42.5 & 60.0 & .1 & 3.2 & 36.3 & 48.8 \\
\hline & Certificate & 34 & 14.2 & 14.2 & 74.2 & .0 & 2.3 & 9.6 & 18.8 \\
\hline & Diploma & 28 & 11.7 & 11.7 & 85.8 & .0 & 2.1 & 7.5 & 15.8 \\
\hline & Degree & 22 & 9.2 & 9.2 & 95.0 & .0 & 1.8 & 5.4 & 12.9 \\
\hline & Post Graduate & 12 & 5.0 & 5.0 & 100.0 & -.1 & 1.4 & 2.5 & 7.9 \\
\hline & Total & 240 & 100.0 & 100.0 & & .0 & .0 & 100.0 & 100.0 \\
\hline \multirow{9}{*}{ Occupation } & Unemployed/Peasant & 52 & 21.7 & 21.7 & 21.7 & .1 & 2.7 & 16.7 & 27.1 \\
\hline & Employee & 64 & 26.7 & 26.7 & 48.3 & -.1 & 2.8 & 21.3 & 32.1 \\
\hline & Business Owner & 40 & 16.7 & 16.7 & 65.0 & .0 & 2.4 & 12.1 & 21.7 \\
\hline & $\begin{array}{l}\text { MMS Agent Booth } \\
\text { Operator }\end{array}$ & 70 & 29.2 & 29.2 & 94.2 & .0 & 3.0 & 22.9 & 35.4 \\
\hline & Other & 14 & 5.8 & 5.8 & 100.0 & .0 & 1.5 & 3.3 & 8.8 \\
\hline & Total & 240 & 100.0 & 100.0 & & .0 & .0 & 100.0 & 100.0 \\
\hline & Less than a year & 68 & 28.3 & 28.3 & 28.3 & -.2 & 2.8 & 22.5 & 33.8 \\
\hline & $1-3$ years & 130 & 54.2 & 54.2 & 82.5 & .3 & 3.1 & 48.3 & 60.8 \\
\hline & $4-6$ years & 40 & 16.7 & 16.7 & 99.2 & .0 & 2.4 & 12.1 & 21.7 \\
\hline Length & 7 years and more & 2 & .8 & .8 & 100.0 & .0 & .6 & .0 & 2.1 \\
\hline Use & Total & 240 & 100.0 & 100.0 & & .0 & .0 & 100.0 & 100.0 \\
\hline Personal & Yes & 118 & 49.2 & 49.2 & 49.2 & .0 & 3.3 & 42.5 & 55.8 \\
\hline Bank & No & 122 & 50.8 & 50.8 & 100.0 & .0 & 3.3 & 44.2 & 57.5 \\
\hline Account & Total & 240 & 100.0 & 100.0 & & .0 & .0 & 100.0 & 100.0 \\
\hline
\end{tabular}




\section{Appendix C}

Table 3. Communalities

\begin{tabular}{|c|c|}
\hline Variables & InitialExtraction \\
\hline 1. MNO Cash Deposit Service & 1.000 .992 \\
\hline 2. MNO Cash Withdraw Service & 1.000 .992 \\
\hline 3. MNO Funds Transfer Service & 1.000 .978 \\
\hline 4. MNO Savings Service & 1.000 .990 \\
\hline 5. MNO Nkongole service & 1.000 .967 \\
\hline 6. MNO International Remittance Service & 1.000 .909 \\
\hline 7. MNO Bill payment Service & 1.000 .983 \\
\hline 8. MNO Airtime Purchase Service & 1.000 .989 \\
\hline 9. Level of Usage - Cash deposit & 1.000 .614 \\
\hline 10. Level of Usage - Cash Withdraw & 1.000 .607 \\
\hline 11. Level of Usage - Funds Transfer & 1.000 .617 \\
\hline 12. Level of Usage - Savings & 1.000 .780 \\
\hline 13. Level of Usage - Access to credit & 1.000 .484 \\
\hline 14. Level of Usage - International remittances & 1.000 .689 \\
\hline 15. Level of Usage - Bill payments & 1.000 .548 \\
\hline 16. Level of Usage - Airtime purchases & 1.000 .766 \\
\hline 17. Only a few MMS access point & 1.000 .638 \\
\hline 18. Insufficient funds/cash at MMS points & 1.000 .671 \\
\hline 19. Insufficient e-float at MMS points & 1.000 .720 \\
\hline 20. MMS is too complex to operate & 1.000 .708 \\
\hline 21. Frequent Network breakdown & 1.000 .653 \\
\hline 22. Lack of interoperability & 1.000 .799 \\
\hline 23. High transaction cost & 1.000 .792 \\
\hline 24. Insecurity to operate MMS & 1.000 .683 \\
\hline 25. Fraud & 1.000 .747 \\
\hline \multicolumn{2}{|c|}{ 26. Collaboration by mobile telephone network operators through interoperability 1.000 .796} \\
\hline 27. Collaboration with other financial services providers & 1.000 .733 \\
\hline 28. Improve MNO Network quality & 1.000 .721 \\
\hline 29. Stronger regulation by financial regulators & 1.000 .682 \\
\hline 30. Enhance the availability of e-banking platforms, mainly POS devices & 1.000 .658 \\
\hline 31. Community education on MMS for financial inclusion & 1.000 .625 \\
\hline 32. Integration of MMS for financial settlements & 1.000 .488 \\
\hline 33. Low/same transaction costs across all channels. & 1.000 .791 \\
\hline
\end{tabular}

Extraction Method: Principal Component Analysis. 


\section{Appendix D}

Table 4. Rotated component matrixa

\begin{tabular}{|c|c|c|c|c|c|c|c|c|}
\hline & \multicolumn{8}{|c|}{ Component } \\
\hline & 1 & 2 & 3 & 4 & 5 & 6 & 7 & 8 \\
\hline 1. MNO Savings Service & .991 & & & & & & & \\
\hline 2. MNO Cash Deposit Service & .988 & & & & & & & \\
\hline 3. MNO Cash Withdraw Service & .988 & & & & & & & \\
\hline 4. MNO Bill payment Service & .988 & & & & & & & \\
\hline 5. MNO Airtime Purchase Service & .986 & & & & & & & \\
\hline 6. MNO Funds Transfer Service & .985 & & & & & & & \\
\hline 7. MNO Nkongole service & .976 & & & & & & & \\
\hline 8. MNO International Remittance Service & .945 & & & & & & & \\
\hline 9. Level of Usage - Savings & & .845 & & & & & & \\
\hline 10. Level of Usage - Airtime purchases & & .844 & & & & & & \\
\hline 11. Level of Usage - Cash deposit & & .700 & & & & & & \\
\hline 12. Level of Usage - Funds Transfer & & .683 & & & & & & \\
\hline 13. Level of Usage - Bill payments & & .566 & & & & & & \\
\hline 14. Level of Usage - Cash Withdraw & & .528 & & & & & & \\
\hline 15. Lack of interoperability & & & .83 & & & & & \\
\hline 16. Insufficient funds/cash at MMS points & & & .778 & & & & & \\
\hline 17. Insufficient e-float at MMS points & & & .75 & & & & & \\
\hline 18. Fraud & & & .61 & & & & & \\
\hline 19. Frequent Network breakdown & & & .59 & & & & & \\
\hline 20. Collaboration by mobile telephone network operators through interoperability & & & & .845 & & & & \\
\hline 21. Collaboration with other financial services providers & & & & .791 & & & & \\
\hline 22. Low/same transaction costs across all channels. & & & & & .835 & & & \\
\hline 23. High transaction cost & & & & & .674 & & & \\
\hline 24. Cost of community education on MMS for financial inclusion & & & & & .653 & & & \\
\hline 25. Insecurity to operate MMS & & & & & & .72 & & \\
\hline 26. Access to credit & & & & & & .58 & & \\
\hline 27. Stronger regulation by financial regulators & & & & & & & .811 & \\
\hline 28. Enhance the availability of e-banking platforms, mainly POS devices & & & & & & & $.71 \mathrm{c}$ & \\
\hline 29. Improve MNO Network quality & & & & & & & & .555 \\
\hline
\end{tabular}

\section{Copyrights}

Copyright for this article is retained by the author(s), with first publication rights granted to the journal.

This is an open-access article distributed under the terms and conditions of the Creative Commons Attribution license (http://creativecommons.org/licenses/by/4.0/). 